\title{
Influence of a customized three-dimensionally printed drill guide on the accuracy of pedicle screw placement in lumbosacral vertebrae: An ex vivo study
}

\author{
Beer, Patricia ; Park, Brian H ; Steffen, Frank ; Smolders, Lucas A ; Pozzi, Antonio ; Knell, Sebastian Christoph
}

\begin{abstract}
Objective: To compare the accuracy of pedicle screw insertion (PSI) into canine lumbosacral vertebrae with custom-made three-dimensionally (3D)-printed drill guides or freehand insertion. Study design: Ex vivo study. Sample population: Nineteen canine lumbosacral specimens. Methods: Drill guides for PSI were designed on the basis of safe screw insertion trajectories by using preoperative computed tomography (CT) and produced by $3 \mathrm{D}$ printing of templates. Right and left sides of the specimens were randomly allocated to two groups; 4-mm pedicle screws were inserted in L5-L6 and L7-S1 spinal segments either freehand (control group) or with custommade drill guides (guide group). Sixty-six screws were inserted with each method. Insertion angles $(\alpha, \beta)$, bone stock, and vertebral canal breach were assessed according to postoperative CT. $\chi 2$ Tests were used to compare vertebral canal breach between groups and vertebrae. Results: Breaches in the vertebral canal were less common $(\mathrm{P}<.001)$ when screws were placed with a guide in the guide group $(9 / 66,14 \%)$ than without a guide $(30 / 66,45 \%)$. The rate of vertebral canal breach differed at L5 $(\mathrm{P}=.021)$ but not at L6 $(\mathrm{P}=.05)$, L7 $(\mathrm{P}=.075)$ or S1 $(\mathrm{P}=.658)$. The angle of insertion $(\alpha)$ did not differ between specimens with and without breaches (guide, $\mathrm{P}=.068$; control, $\mathrm{P}=$ .394). Conclusion: The use of a customized 3D-printed guide generally improved the accuracy of PSI in canine lumbosacral vertebrae, although statistical significance was reached only at L5. Clinical significance: The use of customized drill guides may be considered as an alternative to freehand PSI in the lumbosacral area, especially for L5-L6 vertebrae.
\end{abstract}

DOI: https://doi.org/10.1111/vsu.13417

Posted at the Zurich Open Repository and Archive, University of Zurich

ZORA URL: https://doi.org/10.5167/uzh-190799

Journal Article

Accepted Version

Originally published at:

Beer, Patricia; Park, Brian H; Steffen, Frank; Smolders, Lucas A; Pozzi, Antonio; Knell, Sebastian Christoph (2020). Influence of a customized three-dimensionally printed drill guide on the accuracy of pedicle screw placement in lumbosacral vertebrae: An ex vivo study. Veterinary Surgery, 49(5):977-988.

DOI: https://doi.org/10.1111/vsu.13417 
Article Title: The use of a custom-made 3D-printed drill guide for the insertion of lumbosacral pedicle screws - an ex vivo cadaveric study

Running Head: 3D-printed drill guide for lumbosacral pedicle screw insertion

Patricia Beer, Mag. ${ }^{1}$

Brian H. Park, PhD, MS, BASc ${ }^{1}$

Frank Steffen, Prof., Dr., Dipl. ECVN ${ }^{1}$

Lucas A. Smolders, Dr., $\mathrm{PhD}^{1}$

Antonio Pozzi, Prof., Dr., Dipl. ECVS/ACVS, Dipl. ACVSMR ${ }^{1}$

Sebastian C. Knell, Dr., Dipl. ECVS ${ }^{1}$

${ }^{1}$ Clinic for Small Animal Surgery, Vetsuisse Faculty University of Zurich, Zurich, Switzerland.

\section{Financial support}

This project was not funded.

\section{Conflict-of-interest statement}

The authors declare no conflict of interest related to this report.

\section{Acknowledgements}

Preliminary results were presented as a poster at the 5th World Veterinary Orthopaedic Congress ESVOT-VOS, 19th ESVOT CONGRESS in Barcelona, Spain, from September 12th15 th, 2018.

\section{Correspondence to}

Sebastian Knell

Clinic for Small Animal Surgery

Vetsuisse Faculty University of Zurich

Winterthurerstrasse 260

8057 Zurich, Switzerland

E-Mail: sknell@vetclinics.uzh.ch 


\begin{abstract}
Objectives: To compare the accuracy of pedicle screw insertion into the canine lumbosacral spine using custom-made three-dimensional (3D)-printed drill guides with freehand pedicle screw insertion.
\end{abstract}

Study design: Ex vivo study.

Sample population: Nineteen canine lumbosacral specimens.

Methods: Right and left sides of the specimens were randomly allocated to two groups. Drill guides for pedicle screw insertion were established based on safe screw insertion trajectories using preoperative CT scans and 3D printed. Both the L5-L6 and L7-S1 spinal segments were instrumented using $4 \mathrm{~mm}$ pedicle screws, either freehand (control group) or using the custommade drill guides (guide group). Sixty-six screws were inserted per group. Insertion angles ( $\alpha$, $\beta)$, bone stock, screw entry points, and vertebral canal breach were assessed on postoperative CT scans. Chi-square tests were used to compare the percentages of vertebral canal breach between groups and different vertebral levels.

Results: The total number of screw breaches was lower $(P<.001)$ in the guide group $(9 \%, 14 \%)$ compared to the control $(30 \%, 45 \%)$. A significance was found for L5 $(P=.021)$ and L6 $(P=.05)$. Preoperatively planned and postoperatively measured angles $\alpha$ in the guide-group did not differ for individual vertebrae. The angle $\alpha$ was not diffferent in specimens with and without breaches (guide, $P=.068$; control, $P=.394$ ).

Conclusion: Pedicle screw insertion in canine lumbosacral vertebrae is more accurate using customized 3D-printed drill guides compared with freehand insertion technique.

Clinical significance: Applying custom-made drill guides may be a safe alternative to freehand pedicle screw insertion in dogs with degenerative lumbosacral stenosis or lumbar vertebral fractures. 


\section{Introduction}

Canine degenerative lumbosacral stenosis (DLSS) has been identified as an important cause of back pain in middle-aged, large-breed dogs, and frequently affects working breeds such as the German Shepherd dog (GSD). ${ }^{1-3}$ The pathology of the disease is multifactorial and includes intervertebral disc degeneration, bony and soft-tissue proliferation, vertebral subluxation, and pathological lumbosacral motion. Subsequent spinal canal or intervertebral foraminal stenosis is associated with cauda equina nerve compression manifesting clinically as caudal lumbar or lumbosacral pain, pelvic limb lameness, and neurologic dysfunction. ${ }^{1-3}$

Surgical intervention is recommended if the clinical signs cannot be relieved by conservative treatment because degenerative changes, responsible for the recurrence of clinical signs, are progressing. ${ }^{3-5}$ The surgical goals are to achieve cauda equina decompression directly or indirectly by using stabilizing procedures. ${ }^{1,4,6-8}$ Instrumented stabilization of the lumbosacral spine has been advocated in cases with dynamic compression or in cases in which previous decompressive treatment was ineffective in restoring full limb function or relieving pain, with the aim of stabilizing the affected segments in order to halt progressive degenerative changes. ${ }^{4,5}$ Pedicle screw-rod fixation (PSRF) has been described in veterinary surgery to treat DLSS ${ }^{4,5,8-}$ ${ }^{10}$ and cervical instability in dogs. ${ }^{11}$ In addition, a recent case report describes PSRF in a dog with a thoracic fracture luxation. ${ }^{12}$ Although specific entry points (EP) and angles for safe insertion of pedicle screws into L7 and S1 have been described in Labrador Retrievers, ${ }^{5}$ screw insertion remains difficult ${ }^{10}$ because of variation in pedicle morphometry and vertebral body size of different breeds. ${ }^{13,14}$ In addition, the high incidence of congenital abnormalities such as transitional vertebrae ${ }^{15}$ or the occurrence of secondary degenerative changes may complicate screw placement. The rate of medial vertebral cortex perforation by freehand pedicle screw placement in the L7 and S1 vertebrae has been reported to be as high as $8.3 \%-16.6 \%{ }^{5,9}$ It has been emphasized that safe screw insertion cannot be ensured by adhering to standardized 
guidelines based on anatomical landmarks, necessitating methods to optimize screw placement accuracy. ${ }^{5}$ Increased precision of implant positioning and thus increased safety has been described in the human cervical and lumbosacral spine by applying personalized threedimensional (3D)-printed drill guides. ${ }^{16,17}$ Recently, a high level of accuracy was reported for cervical $^{11}$ and thoracolumbar ${ }^{18}$ spinal stabilization in dogs using 3D-printed drill guides. However, the value of 3D-printed drill guides has not yet been specifically described for the placement of pedicle screws in the caudal lumbar spine and the lumbosacral junction. Therefore, the objectives of this ex vivo study were to evaluate the accuracy and feasibility of 3D-printed drill guides for pedicle screw placement in the vertebral segments L5-L6 and L7S1 of large dogs and to compare it with the freehand technique using previously described trajectories for screw insertion for L7-S1. We hypothesized that (1) the final implant position using a customized 3D-printed drill guide matches the preoperatively planned screw insertion trajectories, and (2) a customized 3D-printed drill guide allows a more accurate placement of pedicle screws into the lumbar and lumbosacral spine compared to freehand drilling. 


\section{Materials and methods}

\section{$\underline{\text { Study subject }}$}

Lumbosacral vertebral specimens of the vertebral segments L5-L6 and L7-S1 from nineteen large-breed dogs with a body weight of over $25 \mathrm{~kg}$ (median, $35 \mathrm{~kg}$; range, 26-60 kg) were used, including those affected with degenerative changes and/or transitional vertebral anomalies. Specimens were excluded if spinal fractures or tumors were present. If one segment was affected with a disease, the intact one was used for investigation. The most common breed was the GSD ( $\mathrm{n}=5)$, with one each of the flat coated retriever, golden retriever, Great Dane, husky, Irish wolfhound, Labrador retriever, Rottweiler, and mixed breed. For six of the specimens, the breed was unknown. Anatomic specimens were collected according to the institution's regulations. All of the dogs were client-owned and were euthanized due to medical reasons unrelated to this study. Dogs were donated for research and teaching purposes by their owners and a written consent was obtained. The vertebral specimens, including the paraspinal muscles, were wrapped in saline soaked swabs and stored at $-18^{\circ} \mathrm{C}$. Specimens were thawed at room temperature 24 hours before use.

The right and left sides of each specimen were randomly allocated (block randomization) to one of the following groups: (1) pedicle screw insertion applying 3D-printed custom-made drill guides (guide group) or (2) freehand pedicle screw insertion as previously described ${ }^{5}$ (control group).

\section{$\underline{\text { Surgical planning }}$}

Preoperative multislice CT scans (Brilliance CT, Philips AG, Zürich, Switzerland) were acquired for each specimen. Exposure settings were $120 \mathrm{kV}$ and $250 \mathrm{mAs}$ and an estimated slice thickness was $1.0 \mathrm{~mm}$ with a pitch of 0.5 and a rotation time of $1 \mathrm{~s}$. The images were stored in DICOM format and imported to the commercial software Mimics ${ }^{\circledR} 20.0$ (Materialise 
MIMICS 20.0, Materialise GmbH, Munich, Germany) for the 3D surgical planning and to create bone models for the segments L5-L6 and L7-S1 (Figure 1). Materialise 3-matic software was used for the development of unilateral drill-guide templates. The drill guides incorporate holes for the insertion of two K-wires and two pedicle screws. The K-wires ensure a tight fit of the drill guides on the vertebrae prior to predrilling of the screw holes, thereby reducing the possibility of slippage between the template and the vertebral surface during drilling (Figure 1). The drill location for the screws and K-wires was planned using 3.5 and $2 \mathrm{~mm}$ diameter cylinders, respectively. Both types of cylinder models (stereolithography format, STL) were pre-made with a length of $15 \mathrm{~cm}$ using Materialise 3-matics and imported into MIMICS 20.0 during planning. Their trajectory was planned directing through the pedicle towards the vertebral body without interfering with the trajectories of the pedicle screws. Optimal screw insertion trajectories including EP and screw angulation were determined by one board certified surgeon (S.C.K.) to achieve a maximal bone stock without neurovascular or endplate violation.

The drill guide template was constructed to mold around the dorsal vertebral arch, the lamina, the spinous process, and in S1 the iliac crest, thereby enabling a "lock-and-key" fit between the guide and vertebral surfaces. To account for remaining soft tissues on the bone after surgical preparation, a latitude of $1 \mathrm{~mm}$ between the inverse surface of the drill guide template and the 3D model of the vertebral surface was chosen. Once the template model was created the cylinders from planned screw and K-wires locations were subtracted out to generate the guided holes for the drill. The drill guide was designed as a unilateral construct, but the dimensions of the template were chosen to incorporate parts of the dorsal aspect of the vertebral arch of the control side. The drill guide models were exported in a STL file and 3D printed with polylactic acid using a 3D printer (3DGENCE ONE, Przyszowice, Poland; https://3dgence.com) with a printing positing precision of 6 microns (Figure 1C,D).

\section{$\underline{\text { Surgical procedure }}$}


Surgery was performed by an experienced surgeon (S.C.K.) with expertise in spinal surgery. In the control group appropriate soft tissue dissection was performed for proper visualization of the screw EPs. Screws were implanted as described using an awl and probes ${ }^{5,8}$ (Synthes, DePuis Synthes, Oberdorf, Switzerland), with two alterations: The pedicle screws in S1 were inserted in a medial-to-lateral fashion directing into the alar wing parallel to the sacroiliac joint to increase bone purchase and minimize the risk of spinal canal penetration. ${ }^{9}$ In addition, during screw insertion no care was given to the perforation of the ventral cortex. The EPs for screws in L5-L6 were defined based on preoperative CT measurements, as there is no published information for pedicle screw insertion at this site. The screw holes in the control group were always drilled first, to avoid influencing drill canal orientation in the control group by following screw orientation in the guide group. After drilling the holes of the drill guide side, screws were inserted into the predrilled holes of the control group to avoid interference with the screws of the guide. Before application of the drill guide soft tissues were dissected until a tight fit on the bone surface was obtained. The drill guide was then fixed on the specimen using two $1.0 \mathrm{~mm}$ K-wires inserted through the dedicated guide canals. After predrilling of the pedicle screw holes through the planned insertion trajectories using a $3.2 \mathrm{~mm}$ drill bit, the holding pins and drill guides were removed and pedicle screws ( $4 \mathrm{~mm}$, Synthes, Switzerland) were inserted on both the control and guide group side. A postoperative CT scan was performed accordingly, and DICOM files were transferred to Mimics to assess screw position by two of the authors (P.B. and S.C.K.). Anatomical dissection was performed in cases in which CT images did not allow clear identification of vertebral cortex breach because of metallic artifacts (Figure 2).

\section{$\underline{\text { Outcome measures }}$}

Pre- and postoperative transverse screw insertion angle alpha $(\alpha)$, medial and lateral, bone stock, and vertebral canal breach were measured on transverse CT images ${ }^{5}$ (Figure 3A,B). Angle $\alpha$ in $\mathrm{S} 1$ was expressed as a negative value due to the inverse screw insertion direction 
compared to L5 and L7. Perforation was defined when the cortex surrounding the vertebral canal was interrupted by any part of the screw. Vertebral canal breach was graded based on a previously described classification and expressed as follows: grade 0 , no vertebral canal breach; grade 1 , minor breach of less than a screw diameter $(\leq 4 \mathrm{~mm})$; grade 2 , severe breach of more than one screw diameter ( $>4 \mathrm{~mm}$; Figure 4$).{ }^{19,20}$ In cases of disagreement about radiographic interpretation between the two observers, a joint assessment was performed to achieve consensus. Bone stock was defined as the length of the medial or lateral screw surface covered by bone. In cases where the screw penetrated the vertebral canal the medial bone stock was measured, including the length of the breach. Screw insertion angle beta $(\beta)^{5}$ and endplate penetration were assessed on sagittal plane images (Figure 3, C), with the images aligned along the cranial endplate of the corresponding vertebrae. The screw EP was subjectively evaluated using a 3D reconstruction of the bone surface. The EP of L7 was assumed to be correct if it was located at the intersection between the line crossing the caudal border of the facet joint and the craniocaudal line crossing the base of the transverse process. Screw EPs of S1 were located in the middle of a line between the caudal border of the cranial articular process and the intermediate sacral crest, as previously described. ${ }^{5,8}$ The assessment of the correct EPs in L5L6 was based upon the preoperatively defined optimal EPs of the CT scans.

\section{$\underline{\text { Data analysis }}$}

Statistical analysis was performed with SPSS 25.0 statistical software (IBM Corporation, Armonk, NY) and GraphPad Prism 7 (GraphPad Software, San Diego, CA). For vertebral canal breach, percentages were calculated for the proportion of screws that showed vertebral canal breach for each group for the different vertebrae. Chi-square tests were used to compare the percentages of vertebral canal breach between the control group and the guide group and between different vertebral levels. 
For the continuous variables, data were presented as median and range. For the variables screw insertion angles and bone stock measurements, the interobserver variability was assessed using a two-way, random intraclass correlation (ICC) model with absolute agreements and a 95\% confidence interval (CI). For further statistical analysis the average values between the measurements of the two raters were used. Normal distribution of the data was assessed using the D'Agostino \& Pearson normality test. Wilcoxon signed rank test was performed to compare measurements of angles and bone stock between the control and drill guide group. MannWhitney test was used to assess the influence of body weight and angle $\alpha$ on the screw breach rate in each treatment group. Correlations between angle $\alpha$ and the medial and lateral bone stock were assessed using Spearman's rank correlation coefficient. $P \leq .05$ was considered statistically significant. 


\section{Results}

\section{Vertebral canal breach}

The vertebral segment L5-L6 was instrumented in 15 and L7-S1 in 18 specimens, making up 132 inserted screws in total (60 in L5-L6, 72 in L7-S1). A total of 39 (29.5\%) screw breaches through the medial vertebral cortex were found (Table 1). The number of screw breaches was lower $(P<.001)$ in the guide group $(9 \%, 14 \%)$ compared to the control group $(30 \%, 5 \%)$. For the individual vertebrae, vertebral canal breach was lower in the guide group compared to the control group for L5 $(P=.021)$ and L6 $(P=.05)$. For L7 $(P=.075)$ and S1 $(P=.658)$, no differences were found between the guide and control groups. The total number of screw breaches in the segments L5 and L6 $(21 \%, 33 \%)$ was not different in comparison to the segments L7 and S1 $(18 \%, 25 \% ; P=.252)$. Grade 2 breaches were only found for screws inserted into L5, L6, and L7. The number of grade 2 breaches did not differ $(P=.096)$ between the guide group $(2,3 \%)$ and control group $(8,12 \%)$. The endplate of L5 and L6 was perforated in two cases (3\%) in the control group. Body weight did not have an influence on the occurrence of vertebral canal breach in the guide group $(P=.805)$ and control group $(P=.766)$.

\section{Angle and bone stock measurements}

Interobserver ICC agreements were 0.995 (CI, 0.993-0.996) for angle $\alpha$; 0.936 (CI, 0.910-0.955) for angle $\beta ; 0.979$ (CI, 0,970-0,985) for the medial bone stock; and 0.977 (CI, 0.968-0.984) for the lateral bone stock, indicating an excellent agreement. For the guide group, insertion angles $\alpha$ did not significantly differ between the preoperatively planned and the postoperatively measured angles L5, L6, L7 or S1, respectively (Table 2). A difference between the pre- and postoperative angles $\beta$ was found for L5 $(P=.022)$, but not for L6, L7 and S1.

In one specimen of the control group the subjectively assessed EP was incorrect. In all other specimens of the two treatment groups EPs were correct. Comparing the angle $\alpha$ between 
the guide and the control group, a significant difference was found in L7 $(P=.01)$ and $\mathrm{S} 1(P=$ .013; Table 3). Angle $\beta$ differed significantly between the guide and the control group in L7 ( $P$ $=.024)$.

The lengths of the medial and lateral bone stock in the guide and the control group were not significantly different for any of the vertebrae (Table 4). Angle $\alpha$ correlated with the length of the medial bone stock in the guide group $\left(\mathrm{r}_{\mathrm{S}}=.338, P=.005\right)$ and in the control group $\left(\mathrm{r}_{\mathrm{S}}=\right.$ $.324 ; P=.008)$. In contrast, angle $\alpha$ did not correlate with the length of the lateral bone stock either in the guide group $\left(\mathrm{r}_{\mathrm{S}}=-1.48 ; P=.237\right)$ or in the control group $\left(\mathrm{r}_{\mathrm{S}}=.221 ; P=.076\right)$.

The angle $\alpha$ was not significantly diffferent in specimens with screw breaches (guide, $16.5^{\circ}\left(8.4-30.2^{\circ}\right)$; control, $\left.20.3^{\circ}\left(0.5-34.7^{\circ}\right)\right)$ in comparison to specimens without screw breaches (guide, $-20.4^{\circ}\left(-0.6-41,5^{\circ}\right)$; control, $\left.18.2^{\circ}\left(3.2-46.5^{\circ}\right)\right)$ in either the guide $(P=.068)$ or the control group $(P=.394)$. 


\section{Discussion}

The insertion of pedicle screws for spinal stabilization is technically demanding in both human and veterinary patients because it is associated with the risk of iatrogenic neurovascular injuries. In this study we showed that the application of customized 3D-printed drill guides for PSRF enhances the accuracy of pedicle screw insertion in canine lumbar and sacral vertebrae and is a safe alternative to freehand pedicle screw placement.

The most severe complications of PSRF arise from screws violating the vertebral canal, causing neurovascular damage. ${ }^{21}$ The use of customized 3D-printed drill guides has been well described in human medicine with a reported risk for vertebral canal breach of $8 \%$ in the lumbar and sacral spine. ${ }^{22,23}$ Hamilton-Bennett et al. (2018) have reported accurate screw placement in 32 pedicle screws inserted in the cervical spine of three dogs by using such 3D-printed drill guides. Only three of these 32 screws perforated the vertebral canal and only to an extent of less than $2 \mathrm{~mm}(9.4 \%) .{ }^{11}$ Likewise, safe screw insertion was achieved in the thoracolumbar spine in 26 of $29(89.6 \%)$ cases in a recent study investigating screw insertion in canine spinal specimen and clinical cases. ${ }^{18}$ These results are comparable to our outcome, with nine out of 66 screws breaching the medial vertebral cortex wall using drill guides (14\%) compared to 30 screws in the control group (45\%).

In our study, the overall perforation rate of greater than $4 \mathrm{~mm}$ was $3 \%$ in the guide group compared to $12 \%$ in the control group; although due to the low number of grade 2 breaches, the statistical power may be too low to find a difference. In human medicine screw perforation of the medial pedicle wall greater than $4 \mathrm{~mm}$ is critical and considered as creating a high risk for damage of neurovascular structures. ${ }^{24,25}$ However, currently no such clinical guidelines are available for canine patients. To classify the severity of vertebral canal breach we used a modified grading system based on a classification related to the size of the screws. ${ }^{19}$ This 
grading may increase the comparability between studies in the future, although its clinical relevance is unknown.

We found that freehand drilling was less accurate in L5-L6 screw placement compared to L7-S1 and that all breaches over $4 \mathrm{~mm}$ were detected in L5-L6. Based on the low incidence of breaches in the drill guide group, the use of the drill guides could substantially reduce the number of vertebral canal breaches in these vertebrae. Complicating factors in the L5-L6 segment are the relatively small size of the pedicle, leaving only a small safe corridor for implants. Even if our primary focus was the assessment of 3D-printed drill guides for PSRF of the lumbosacral junction to treat dogs with DLSS, we included the vertebral segment L5-L6 in our analysis because it can be assumed that PSRF in L5-L6 is more challenging. There are no existing guidelines for pedicle screw placement in L5-L6, anatomical knowledge is limited, and surgeons are not experienced in placing pedicle screws in these vertebrae. Although the use of drill guides could not significantly reduce the rate of screw breaches in L7-S1 as it did in L5L6, the number of breaches was still lower (guide, 5 14\%; control, 13 36\%). Custom-made drill guides may have even more relevance in L5-L6. Our conclusion is similar to that of a metaanalysis investigating pedicle screw placement accuracy in people. Screw placement in the thoracic spine has been shown to be more difficult than in the cervical or lumbar spine and may result from the smaller pedicle diameters. ${ }^{21}$

Malpositioning of screws might be caused by an incorrect EP, incorrect screw angulation, or inappropriate screw dimensions in relation to the pedicle width. Changing either the EP or the insertion angles, especially in the transversal plane (angle $\alpha$ ), may increase the risk for spinal cord or vascular injury if the EP or the angle remains unchanged. In the control group we adhered to angles and EPs defined by Smolders et al. (2011), ${ }^{5}$ while those of the drill group were altered according to the individual anatomy based on preoperative CT images. No association was seen in the drill group as both EPs and angles can be changed rather easily 
during preoperative drill guide planning under precise consideration of the individual anatomy. Adhering to specific pedicle screw orientation and EPs is consequently more essential during freehand screw insertion than in cases in which customized drill guides are applied.

A direct comparison of preoperatively planned insertion trajectories and postoperatively assessed screw position showed that pedicle screws can be placed precisely in terms of screw angulation and EPs if customized 3D-printed drill guides are applied, in both the caudal lumbar spine and the sacrum. The technique's high level of accuracy for the placement of pedicle and vertebral body screws has already been demonstrated for the canine cervical ${ }^{11}$ and thoracolumbar $^{18}$ spine, indicating its applicability in multiple, anatomically variable, localizations of the spine. ${ }^{18}$

A tight fit of the guide on the bone surface is crucial for precise drilling. This is achieved by the ventral surface having an inverse shape of the anatomical bone structures. The drill guide was shaped around the complete bone surface of the vertebral arch and spinous processes, encompassing the iliac crest in L7-S1 drill guides. The iliac crest is easy to identify intraoperatively by palpation and can be cleaned safely from attached soft tissues without a major risk of neuronal or vascular injury. As we assigned the right and left side of the instrumented segments to either the control or the drill group, the drill guides were planned as a unilateral construct. An even better fit may be achieved by including both sides of the vertebral arch. Additionally, all soft tissues need to be stripped from the bone surface as an inappropriate preparation can result in an inaccuracy of the drill holes and subsequent neurovascular violation. Preparation may be more invasive and time consuming compared to freehand screw insertion. However, in human studies it was shown that the overall surgical time is not prolonged but rather reduced because of the increased simplicity of intraoperative screw placement. ${ }^{26}$

Before 3D-printed drill guides can be applied it must be considered that specific programs and equipment, as well as the expertise to use them, are required. ${ }^{26}$ Preoperative 
planning and printing of the guides is time consuming - the process from the preoperative CT scan to the sterilized drill guide takes at least 1 day. Thus, the technique is rather useful for elective procedures or stable patients with traumatic spinal fractures. According to a recent systematic review about 3D printing in human spinal surgery, manufacturing can last from 16 hours up to 7 days and the costs range between $\$ 20$ and $\$ 400 .{ }^{26}$ We did not assess costs to manufacture the drill guides, but if infrastructure and expertise are available, additional costs are moderate and affordable for owners. The time required to design a custom-made drill guide in this study was about 30 to 60 minutes. Nevertheless, it must be considered that we planned only unilateral drill guides, and thus the printing time might be considerably longer for clinical patients.

Our study results are limited because of the cadaveric study design, small sample size, and unknown clinical significance of pedicle screw vertebral canal breaches. We did not assess screw anchorage in the trans-cortex and the lateral pedicle wall, and it should be taken into account that optimal screw anchorage is dependent on the involvement of the cis- and transcortex, as well as the medial and lateral pedicle wall. ${ }^{4,5,9}$ All specimens were instrumented with the same screw size as we did not perform preoperative measurements of the pedicle width. Therefore, some of the inserted screws may have been slightly oversized in the smaller samples.

We conclude that a 3D-printed drill guide increases safety for PRSF placement in the canine lumbosacral spine. While adhering to predefined screw insertion angles and EPs is essential during freehand screw insertion, 3D-printed drill guides make individualized adjustments of the proposed EPs and screw insertion angles feasible and safe. Insertion angles as planned preoperatively using 3D software are comparable to the surgical results. Printing 3D drill guides may be a useful tool to overcome the high risk of a malpositioned screw, especially for inexperienced surgeons and in cases where screw placement is demanding and a high vertebral breach risk is expected. 


\section{Conflict-of-interest statement}

The authors declare no conflict of interest related to this report. 


\section{References}

1. Meij BP, Bergknut N. Degenerative lumbosacral stenosis in dogs. Vet Clin North Am Small Anim Pract. 2010; 40: 983-1009.

2. Ness MG. Degenerative lumbosacral stenosis in the dog: A review of 30 cases. J Small Anim Pract. 1994; 35: 185-190.

3. Danielsson F, Sjostrom L. Surgical treatment of degenerative lumbosacral stenosis in dogs. Vet Surg. 1999; 28: 91-98.

4. Tellegen AR, Willems N, Tryfonidou MA, et al. Pedicle screw-rod fixation: a feasible treatment for dogs with severe degenerative lumbosacral stenosis. BMC Vet Res. 2015; 11: 299 .

5. Smolders LA, Voorhout G, van de Ven R, et al. Pedicle screw-rod fixation of the canine lumbosacral junction. Vet Surg. 2012; 41: 720-732.

6. Jeffery ND, Barker A, Harcourt-Brown T. What progress has been made in the understanding and treatment of degenerative lumbosacral stenosis in dogs during the past 30 years? Vet $J .2014$; 201: 9-14.

7. Teunissen M, van der Veen AJ, Smit TH, et al. Effect of a titanium cage as a stand-alone device on biomechanical stability in the lumbosacral spine of canine cadavers. Vet $J$. $2017 ; 220: 17-23$.

8. Meij BP, Suwankong N, Van der Veen AJ, et al. Biomechanical flexion-extension forces in normal canine lumbosacral cadaver specimens before and after dorsal laminectomydiscectomy and pedicle screw-rod fixation. Vet Surg. 2007; 36: 742-751.

9. Zindl C, Litsky AS, Fitzpatrick N, et al. Kinematic behavior of a novel pedicle screw-rod fixation system for the canine lumbosacral joint. Vet Surg. 2018; 47: 114-124. 
10. Simon A, Easley JT, McGilvray K, et al. Biomechanical Comparison of Three Lumbosacral Stabilizing Implant Devices in Canine Cadavers. Vet Comp Orthop Traumatol. 2018; 31: A3609.

11. Hamilton-Bennett SE, Oxley B, Behr S. Accuracy of a patient-specific 3D printed drill guide for placement of cervical transpedicular screws. Vet Surg. 2018; 47: 236-242.

12. Özak A, Yardimci C, Nisbet HÖ, et al. Treatment of Traumatic Thoracal Instability with Pedicle Screw-Rod Fixation System in a Dog. J Fac Vet Med. 2018; 4: 627-630.

13. Watine S, Cabassu JP, Catheland S, et al. Computed tomography study of implantation corridors in canine vertebrae. J Small Anim Pract. 2006; 47: 651-657.

14. Morgan JP, Atilola M, Bailey CS. Vertebral canal and spinal cord mensuration: a comparative study of its effect on lumbosacral myelography in the dachshund and German shepherd dog. J Am Vet Med Assoc. 1987; 191: 951-957.

15. Fluckiger MA, Damur-Djuric N, Hassig M, et al. A lumbosacral transitional vertebra in the dog predisposes to cauda equina syndrome. Vet Radiol Ultrasound. 2006; 47: 39-44.

16. Lu S, Xu YQ, Zhang YZ, et al. A novel computer-assisted drill guide template for lumbar pedicle screw placement: a cadaveric and clinical study. Int J Med Robot. 2009; 5: 184191.

17. Ma T, Xu YQ, Cheng YB, et al. A novel computer-assisted drill guide template for thoracic pedicle screw placement: A cadaveric study. Arch Orthop Trauma Surg 2012; 132: 6572.

18. Fujioka T, Nakata K, Nishida H, et al. A novel patient-specific drill guide template for stabilization of thoracolumbar vertebrae of dogs: cadaveric study and clinical cases. Vet Surg. 2018.

19. Schizas C, Michel J, Kosmopoulos V, et al. Computer tomography assessment of pedicle screw insertion in percutaneous posterior transpedicular stabilization. Eur Spine J. 2007; 16: 613-617. 
20. Wiesner L, Kothe R, Schulitz KP, et al. Clinical evaluation and computed tomography scan analysis of screw tracts after percutaneous insertion of pedicle screws in the lumbar spine. Spine. 2000; 25: 615-621.

21. Kosmopoulos V, Schizas C. Pedicle screw placement accuracy: A meta-analysis. Spine. 2007; 32: E111-E120.

22. Merc M, Recnik G, Krajnc Z. Lumbar and sacral pedicle screw placement using a template does not improve the midterm pain and disability outcome in comparison with free-hand method. Eur J Orthop Surg Traumatol. 2017; 27: 583-589.

23. Merc M, Drstvensek I, Vogrin M, et al. A multi-level rapid prototyping drill guide template reduces the perforation risk of pedicle screw placement in the lumbar and sacral spine. Arch Orthop Trauma Surg. 2013; 133: 893-899.

24. Gertzbein SD, Robbins SE. Accuracy of pedicular screw placement in vivo. Spine. 1990; 15: 11-14.

25. Perna F, Borghi R, Pilla F, et al. Pedicle screw insertion techniques: an update and review of the literature. Musculoskelet Surg. 2016; 100: 165-169.

26. Wilcox B, Mobbs RJ, Wu AM, et al. Systematic review of 3D printing in spinal surgery: the current state of play. J Spine Surg. 2017; 3: 433-443. 


\section{Figure legends}

Figure 1: Preoperative planning of a 3D-printed drill guide for the right side of the segments L5-L6 and L7-S1 using multislice CT scans exported to a 3D-planning software (Materialise GmbH V20.0, Munich, Germany; A-B). Screw entry and K-wire insertion points as well as screw and K-wire trajectories were defined in the tangential, transversal and sagittal plane (A) and corresponding cylinders were planned in a 3D model (B). The drill guide template was constructed with a surface designed to be inverse to the dorsal vertebral surface of L5-L6 or L7-S1, including two holes for predrilling of the pedicle screw canals and two holes for temporary K-wire fixation of the guide on the bone surface. (C) Dorsal view on a specimen with a customized drill guide for the right side of the segment L7-S1. (D) Dorso-lateral view on a specimen with drill guides for L5-L6 and L7-S1.(cr, cranial; cd, caudal; le, left; ri, right.)

Figure 2: Anatomical confirmation of pedicle screw position: Lateral view (A), dorsal view (B), and transverse cut (C) of a pedicle screw inserted in the right pedicle of an L6 vertebra. The entry point of the screw is located at the intersection between the line crossing the caudal border of the facet joint and the craniocaudal line crossing the base of the transverse process (A and B). The pedicle screw is not penetrating the vertebral canal and its shaft is covered by sufficient bone stock medially and laterally (C). Ideal screw position in S1 achieving maximal medial and lateral bone stock without vertebral canal breach is shown in (D). For S1, the screw insertion angle $\alpha$ was defined as a negative value as screws were inserted in mediodorsal to lateroventral direction compared to L5 to L7, where screws were oriented in a laterodorsal to medioventral direction. 
Figure 3: Insertion angle and bone stock measurements on postoperative CT images for lumbar vertebrae (A, C) and S1 (B). Angle alpha ( $\alpha$ ) was defined as the angle between the sagittal plane and a line across the screw axis assessed on transverse $\mathrm{CT}$ images (A and B). Bone stock (bs) was defined as the length of the medial (a) or lateral (b) screw surface covered by bone (A and B). Angle beta $(\beta)$ is the angle between a line along the cranial vertebral endplate and the screw axis in the sagittal plane $(\mathrm{C})$.

Figure 4: Illustrative classification of screw position with anatomical transversal or sagittal sections and corresponding postoperative transversal CT images. Grade 0, no vertebral canal breach (A); grade 1, breach of the medial vertebral canal bone cortex of $<1$ screw diameter (B); grade 2 , breach of $>1$ screw diameter $(\mathrm{C})$. 


\section{Tables}

Table 1: Total and relative numbers of screws with or without a vertebral canal breach divided into the different grades (grade 0 , no vertebral canal breach; grade 1, minor breach of $\leq 4 \mathrm{~mm}$; grade 2 , severe breach of $>4 \mathrm{~mm}$ ) for the control and guide group. $P$-values obtained for the statistical tests comparing the control with the guide group are displayed. $P \leq .05$ are displayed in bold text.

\begin{tabular}{|c|c|c|c|}
\hline \multirow[t]{2}{*}{ Vertebra } & \multicolumn{2}{|c|}{ Grade of vertebral canal breach } & \multirow[t]{2}{*}{$P$-value } \\
\hline & Control group & Guide group & \\
\hline L5 $(n=15)$ & $\begin{array}{l}\text { Grade } 0: 6(40 \%) \\
\text { Grade 1: } 5(33 \%) \\
\text { Grade 2: } 4(27 \%)\end{array}$ & $\begin{array}{l}\text { Grade } 0: 13(87 \%) \\
\text { Grade } 1: 1(7 \%) \\
\text { Grade 2: } 1(7 \%)\end{array}$ & .021 \\
\hline $\mathrm{L} 6(\mathrm{n}=15)$ & $\begin{array}{l}\text { Grade } 0: 7(47 \%) \\
\text { Grade 1: } 6(40 \%) \\
\text { Grade 2: } 2(13 \%)\end{array}$ & $\begin{array}{l}\text { Grade } 0: 13(87 \%) \\
\text { Grade } 1: 1(7 \%) \\
\text { Grade 2: } 1(7 \%)\end{array}$ & .050 \\
\hline L7 $(n=18)$ & $\begin{array}{l}\text { Grade } 0: 9(50 \%) \\
\text { Grade 1: } 7(39 \%) \\
\text { Grade 2: } 2(11 \%)\end{array}$ & $\begin{array}{l}\text { Grade } 0: 15(83 \%) \\
\text { Grade } 1: 3(17 \%) \\
\text { Grade } 2: 0(0 \%)\end{array}$ & .075 \\
\hline $\mathrm{S} 1(\mathrm{n}=18)$ & $\begin{array}{l}\text { Grade } 0: 14(78 \%) \\
\text { Grade 1: } 4(22 \%) \\
\text { Grade 2: } 0(0 \%)\end{array}$ & $\begin{array}{l}\text { Grade } 0: 16(89 \%) \\
\text { Grade } 1: 2(11 \%) \\
\text { Grade 2: } 0(0 \%)\end{array}$ & .658 \\
\hline Total $(n=66)$ & $\begin{array}{l}\text { Grade } 0: 36(55 \%) \\
\text { Grade } 1: 22(33 \%) \\
\text { Grade } 2: 8(12 \%)\end{array}$ & $\begin{array}{l}\text { Grade } 0: 57(86 \%) \\
\text { Grade 1: } 7(11 \%) \\
\text { Grade 2: } 2(3 \%)\end{array}$ & .0002 \\
\hline
\end{tabular}


Table 2: Median and range $\left(^{\circ}\right)$ of pre- and postoperatively measured insertion angles $\alpha$ and $\beta$ in the guide group. $P$-values for comparison of the pre-and postoperative angles are displayed. $P \leq .05$ are displayed in bold text.

\begin{tabular}{|c|c|c|c|c|c|c|c|c|}
\hline & \multicolumn{4}{|l|}{ Angle $\alpha$} & \multicolumn{4}{|l|}{ Angle $\beta$} \\
\hline & L5 & L6 & L7 & $\mathrm{S} 1$ & L5 & L6 & L7 & $\mathrm{S} 1$ \\
\hline $\begin{array}{l}\text { Pre- } \\
\text { operative }\end{array}$ & $\begin{array}{l}28.2 \\
(10.9-38.3) \\
\end{array}$ & $\begin{array}{l}20.2 \\
(7.6-37.6) \\
\end{array}$ & $\begin{array}{l}17.7 \\
(6.2-36.2) \\
\end{array}$ & $\begin{array}{l}-9.3 \\
(-19.9--1) \\
\end{array}$ & $\begin{array}{l}10.9 \\
(7.2-20.9) \\
\end{array}$ & $\begin{array}{l}6.5 \\
(-5-16) \\
\end{array}$ & $\begin{array}{l}6.7 \\
(0.2-25.3) \\
\end{array}$ & $\begin{array}{l}16.5 \\
(2.4-23.1)\end{array}$ \\
\hline $\begin{array}{l}\text { Post- } \\
\text { operative }\end{array}$ & $\begin{array}{l}29.3 \\
(11.6-38.7) \\
\end{array}$ & $\begin{array}{l}24.9 \\
(7.6-41.5)\end{array}$ & $\begin{array}{l}20.3 \\
-0.6-29.1)\end{array}$ & $\begin{array}{l}-12.6 \\
(-20.4--1)\end{array}$ & $\begin{array}{l}9.5 \\
(-4.5-28.2)\end{array}$ & $\begin{array}{l}8.9 \\
(-3.3-21.7)\end{array}$ & $\begin{array}{l}7.2 \\
(-4.2-18.2)\end{array}$ & $\begin{array}{l}14.7 \\
(5.4-22.1)\end{array}$ \\
\hline$P$-value & .552 & .847 & .196 & .185 & .022 & .446 & .101 & .279 \\
\hline
\end{tabular}


Table 3: Median and range $\left({ }^{\circ}\right)$ of postoperatively measured insertion angles $\alpha$ and $\beta$ in the control and guide group. $P$-values for comparison of the pre-and postoperative angles have been displayed. $P \leq .05$ are displayed in bold text.

\begin{tabular}{|c|c|c|c|c|c|c|c|c|}
\hline & \multicolumn{4}{|l|}{ Angle $\alpha$} & \multicolumn{4}{|l|}{ Angle $\beta$} \\
\hline & L5 & L6 & L7 & S1 & L5 & L6 & L7 & S1 \\
\hline $\begin{array}{l}\text { Guide } \\
\text { group }\end{array}$ & $\begin{array}{l}29.3 \\
(11.6-38.7) \\
\end{array}$ & $\begin{array}{l}24.9 \\
(7.6-41.5) \\
\end{array}$ & $\begin{array}{l}20.3 \\
-0.6-29.1) \\
\end{array}$ & $\begin{array}{l}-12.6 \\
(-20.4--1) \\
\end{array}$ & $\begin{array}{l}9.5 \\
(-4.5-28.2) \\
\end{array}$ & $\begin{array}{l}8.9 \\
(-3.3-21.7) \\
\end{array}$ & $\begin{array}{l}7.2 \\
(-4.2-18.2) \\
\end{array}$ & $\begin{array}{l}14.7 \\
(5.4-22.1) \\
\end{array}$ \\
\hline $\begin{array}{l}\text { Control } \\
\text { group }\end{array}$ & $\begin{array}{l}23.8 \\
(6.8-46.9)\end{array}$ & \begin{tabular}{|l|}
24.7 \\
$(3.2-32.3)$ \\
\end{tabular} & $\begin{array}{l}15.3 \\
(0.5-23.9)\end{array}$ & $\begin{array}{l}-17.0 \\
(-29.6--5) \\
\end{array}$ & $\begin{array}{l}7.5 \\
(0-16.7)\end{array}$ & $\begin{array}{l}7.9 \\
(3.1-19.3)\end{array}$ & \begin{tabular}{|l|}
11.8 \\
$(3.4-30.4)$ \\
\end{tabular} & $\begin{array}{l}13.4 \\
(-2-32.5)\end{array}$ \\
\hline$P$-value & .421 & .583 & .010 & .013 & .421 & .859 & .024 & .399 \\
\hline
\end{tabular}


Table 4: Median and range of postoperatively measured medial and lateral bone stock $(\mathrm{mm})$ in the control and guide group. No significant differences between the groups were found.

\begin{tabular}{|c|c|c|c|c|c|c|c|c|}
\hline & \multicolumn{4}{|c|}{ Medial bone stock } & \multicolumn{4}{|c|}{ Lateral bone stock } \\
\hline & L5 & L6 & L7 & S1 & L5 & L6 & L7 & $\mathrm{S} 1$ \\
\hline $\begin{array}{l}\text { Guide } \\
\text { group }\end{array}$ & $\begin{array}{l}21.25 \\
(4.6-37.0)\end{array}$ & $\begin{array}{l}25.1 \\
(18.3-38.0)\end{array}$ & $\begin{array}{l}27.0 \\
(14.1-42.4) \\
\end{array}$ & $\begin{array}{l}18.4 \\
(14.2-27.1)\end{array}$ & $\begin{array}{l}8.95 \\
(3.2-23.0)\end{array}$ & $\begin{array}{l}9.5 \\
(2.9-24.4)\end{array}$ & $\begin{array}{l}16.5 \\
(6.2-27.2)\end{array}$ & $\begin{array}{l}22.9 \\
(16.8-31.6)\end{array}$ \\
\hline $\begin{array}{l}\text { Control } \\
\text { group }\end{array}$ & $\begin{array}{l}24.9 \\
(18,1-32.2)\end{array}$ & $\begin{array}{l}23.8 \\
(17.8-34.7) \\
\end{array}$ & $\begin{array}{l}25.5 \\
(10.5-32.8) \\
\end{array}$ & $\begin{array}{l}19.25 \\
(13.8-26.5)\end{array}$ & $\begin{array}{l}15.7 \\
(5.8-6.0) \\
\end{array}$ & $\begin{array}{l}10.4 \\
(2.9-26.0) \\
\end{array}$ & $\begin{array}{l}15.9 \\
(2.9-20) \\
\end{array}$ & $\begin{array}{l}21.1 \\
(16.3-34.9) \\
\end{array}$ \\
\hline$P$-value & .296 & .600 & .145 & .840 & .615 & .840 & .426 & .207 \\
\hline
\end{tabular}

